\title{
ФОРМУВАННЯ КУЛЬТУРИ ІНТЕРНЕТ-КОМУНІКАЦЇ̈ У МАЙБУТНІХ ЕКОНОМІСТІВ
}

\section{Т. Б. Поясок, О. І. Беспарточна}

Кременчуцький національний університет імені Михайла Остроградського,

вул. Першотравнева, 20, м. Кременчук, 39614, Україна. E-mail: poyasoktb@ukr.net

Обгрунтовано теоретичні основи Інтернет-комунікації як специфічного процесу взаємообміну інформацією; доведено актуальність оволодіння майбутнім економістом культурою Інтернет-комунікації як інтегральним утворенням, що забезпечує кваліфіковане виконання професійної комунікативної діяльності; показано, що способом виявлення поваги до партнера з Інтернет-комунікації є дотримання правил мовного та мережного етикету; розкрито сутність феномену «культура Інтернет-комунікації»; представлено розроблену методику формування у майбутніх економістів культури Інтернет-комунікації; схарактеризовано іiі складники та обгрунтовано вибір технологій, що сприяють ії реалізації. Здійснено зіставлення отриманих під час проведення педагогічного експерименту результатів і показано, що реалізація методики формування у майбутніх економістів культури Інтернет-комунікації привела до суттєвих статистично значущих змін у рівні їі сформованості.

Ключові слова: Інтернет-комунікації, культура, економісти, технологія, методика, мовний етикет, мережевий етикет.

\section{ФОРМИРОВАНИЕ КУЛЬТУРЫ ИНТЕРНЕТ-КОММУНИКАЦИИ У БУДУЩИХ ЭКОНОМИСТОВ}

\section{Т. Б. Поясок, Е. И. Беспарточная}

Кременчугский национальный университет имени Михаила Остроградского

ул. Первомайская, 20. г. Кременчуг, 39614, Украина. E-mail: poyasoktb@ukr.net

ОбоснованытеоретическиеосновыИнтернет-коммуникациикакспецифическогопроцесса взаимного обмена информацией; доказано актуальность овладения будущим экономистом культурой Интернет-коммуникации как интегральным образованием, которое обеспечивает квалифицированное исполнение профессиональной коммуникативной деятельности; показано, что методом проявления уважения к партнеру по Интернет-коммуникации является соблюдение правил языкового и селевого этикета; раскрыта сущность феномена «культура Интернеткоммуникации»; представлено разработанную методику формирования у будущих экономистов культуры Интернет-коммуникациии; охарактеризованы ее компоненты и обоснованы выборы технологий, способствующих её реализации. Осуществлено сопоставление полученных вовремя проведения педагогического эксперимент результатов и показано, что внедрение методики формирования у будущих экономистов культуры Интернеткоммуникации привело к значительным статистически значимым изменениям в уровне ее сформированности.

Ключевые слова: Интернет-коммуникация, культура, экономисты, технология, методика речевой этикет, сетевой этикет.

АКТУАЛЬНІСТЬ РОБОТИ. Соціально-економічні і духовні процеси, що відбуваються на тлі «інформаційного вибуху», ставлять перед освітньою діяльністю завдання забезпечити підготовку людини до життя у світі багатоманітних зв'язків, починаючи 3 контактів 3 найближчим оточенням- до міжкультурних комунікацій. Соціально-економічні перетворення, процеси глобалізації, інтеграції, демократизації та інформатизації сучасного суспільства, підвищення ролі інформації і знань у його розвитку висувають принципово нові вимоги до професійної підготовки фахівців з вищою освітою, фахова діяльність яких особливо підлягає модернізації, оскільки відбувається у контексті змін та тенденцій постіндустріального суспільства. Якісне виконання цих вимог на сучасному етапі неможливе без широкого використання Інтернет-технологій та Інтернеткомунікації, що дозволить фахівцям 3 економіки ефективно організовувати діалог із реальними і віртуальними партнерами, застосовуючи вербальні і невербальні засоби комунікації, використовуючи можливості комп'ютерних мереж.

Сучасний економіст повинен не тільки застосовувати інформаційні технології у професійній діяльності, а й використовувати комплекс комунікативних послуг, передбачених інформаційним середовищем, а також необмежені інформаційні ресурси. Такі вимоги до сучасного економіста призвели до необхідності формування висококомпетентного фахівця нової генерації, здатного до необмеженої Інтернет-комунікації, який був би носієм ефективних форм взаємодії із суб’єктами економічної діяльності.

Проблеми удосконалення професійної підготовки майбутніх економістів досліджували ряд науковців, зокрема, О. Войнаровська [1], Р. Гейзерська [2], О. Ельбрехт [3], Т. Поясок [4] та ін. У попередніх дослідженнях ми доводили, що у нових соціальноекономічних умовах все більш очевидними стають протиріччя між змістом економічної освіти і зміною потреб галузей економіки і соціальної сфери, між рівнем професійної економічної освіти та можливістю працевлаштування молодих фахівців [4]. Поряд 3 цим, невизначеність соціальних норм, розмаїття засобів комунікації та видів діяльності, опосередкованої мережею Інтернет, роблять важливою галуззю дослідження Інтернет-середовище, зокрема щодо детермінант комунікації та поведінки.

Аналіз останніх досліджень і публікацій. Аналіз наукової літератури з філософії, психології, педагогіки, культурології щодо трактування поняття «культура», дозволив констатувати, що, залежно від підходу до вивчення, воно включає різні аспекти. Для нашого дослідження ми послуговувалися визначенням, запропонованим В. М. Гриньовою, яка трактує поняття «культура» як специфічно людський спосіб буття, який визначає весь спектр практи- 
чної та духовної активності людини, іiі можливої взаємодії з навколишнім світом і з собою [5]. Оскільки культура $\epsilon$ якісним показником діяльності, особистісну культуру можна охарактеризувати як процес накопичення знань, досвіду і якісної реалізації у діяльності і поведінці. Одним із поведінкових проявів культури $є$ комунікація. Так американський науковець Е. Холл, досліджуючи проблеми міжкультурної комунікації, дійшов висновку, що культура - це комунікація, а комунікація - це культура [6]. Отже, процес комунікації потребує опанування культури міжлюдської взаємодії.

Оскільки комунікація включає як процес самостійного пошуку інформації, так і ії використання 3 метою самовдосконалення, вона може спрямовувати свої посили як до окремої особистості (приймача), так і до великої кількості партнерів 3 комунікації (відомих або можливих). У цьому аспекті ми погоджуємось із тлумаченням поняття комунікації $\mathrm{H}$. Волковою, яка трактує його як специфічний процес взаємообміну інформацією у системах «людиналюдина», «людина-комп'ютер», «людина-комп'ютер-людина» [7], тобто розвиток Інтернету як засобу взаємодії між людьми призвів до специфічного виду спілкування Інтернет-комунікації, яку називають також комунікацією в електронному середовищі, «електронною комунікацією», «комп'ютерно опосередкованою комунікацією», «людино-комп'ютерною взаємодією» тощо. На думку I. Розіної, комп'ютерно-опосередкована комунікація є міждисциплінарним напрямом теорії і практики комунікаціï, у якому досліджується використання людьми електронних повідомлень для формування розуміння у різноманітних середовищах, контекстах і культурах; процес, що відбувається у відкритому електронному соціальному середовищі [8].

Процес становлення як теорії і практики комунікації в цілому, так і Інтернет-комунікації зокрема, відбувався на підгрунті міждисциплінарних досліджень, у проведенні яких беруть участь фахівці різних галузей. Так дослідник у галузі телебачення Дж. Мировіц описав вторгнення телебачення в оселі, його психологічний вплив, аналогічний зустрічі вічна-віч, коли створюється враження знайомства 3 телеведучими чи акторами. Цей феномен науковець назвав «парасоціальна взаємодія» [9]. Одним 3 передвісників використання комп'ютера як комунікативного середовища в аспекті автоматизації роботи офісу був С.Баренс [9], дослідження якого стали підгрунтям для концептуальної ідеї мережі Інтернет, можливості реалізації комунікації в електронному середовищі.

Однією зі значущих характеристик Інтернеткомунікації $\epsilon$ підтримка інтерактивної взаємодії у мережі, що передбачає взаємодію між людьми, між користувачами й інформаційними ресурсами. Така взаємодія найчастіше асоціюється із запропонованою Ф. Денсом метафорою спіралі комунікації: комунікація постійно базується на попередньому досвіді, що впливає на майбутню комунікацію, зокрема Інтернет-комунікацію, за якої взаємодія будується через деякий час, та постійний обмін інформацією [10]. Не зважаючи на численні дослідження функціонування Інтернет-середовища, професійної підготовки фахів- ців економічного профілю, відкритими залишаються проблеми формування у майбутніх фахівців,зокрема 3 економіки, культури комунікації, опосередкованої мережею Інтернет, змісту і прийомів формування комунікативної компетентності, підвищення комунікативної культури користувачів мережі Інтернет у процесі професійної діяльності тощо.

Метою статті $\epsilon$ теоретичне обгрунтування процесу формування у майбутніх економістів культури Інтернет-комунікації та розробка методики реалізації цього процесу.

МАТЕРІАЛ I РЕЗУЛЬТАТИ ДОСЛІДЖЕНЬ. Проаналізувавши дослідження науковців, ми виділили три типи Інтернет-комунікації, які здійснює сучасний економіст, що представлено на рис. 1.

Інтерактивні форми взаємодії в Інтернет-комунікації вимагають відповідної культури їх здійснення.

Головним засобом обміну інформацією в Інтернет-мережах є писемне мовлення, як безпосереднє, так і відтерміноване. Воно повинне компенсувати відсутність інформації, яку надають візуальні образи партнерів. Писемне мовлення має як переваги, так недоліки відносно усного. Так до переваг можна віднести наявність значного терміну для обмірковування і формулювання своїх думок, добору аргументів, можливість коригувати текст, точність у висловлюванні думок, їх збереження на майбутнє. Недоліками писемного мовлення $\epsilon$ відсутність безпосереднього контакту зі співрозмовником, його візуальних характеристик, можливості побачити, як сприймаються висловлені думки комунікантом, і перебудувати висловлювання залежно від його реакції.

Інтернет-комунікації переважно являють собою поєднання усно-писемного мовлення. Наприклад, web-сайти здебільшого представлені писемним мовленням, а синхронні chat-конференції наділені особливостями усного. Деякі дослідники комп'ютерноопосередкованій мовній діяльності надають статус абсолютно нової форми комунікації, відокремлюючи іiі від усної та писемної. Зважаючи на це, специфічні особливості мовної діяльності у мережі Інтернет повинні враховуватись і при формуванні культури Інтернет-комунікації фахівців з економіки.

Майбутній економіст, насамперед, повинен володіти культурою пошуку у мережі Інтернет, яка грунтується на опануванні такими знаннями й уміннями, як:

- побудова і функціонування комп'ютерних мереж;

- основна термінологія комп'ютерних мереж;

- основні характеристики мережі Інтернет;

- апаратні, програмні та інформаційні ресурси Інтернет;

- методи доступу до інформаційного середовища;

- основні форми взаємодії у мережі;

- можливість ідентифікації користувачів;

- принципи об'єднання комп'ютерів у мережі;

- типи, призначення та принципи роботи пошукових систем; адреси їх основних серверів;

- принципи розташування інформації на пошукових серверах та правила створення запитів на пошук необхідної інформації;

- використання інформаційних ресурсів комп'ютерних технологій. 


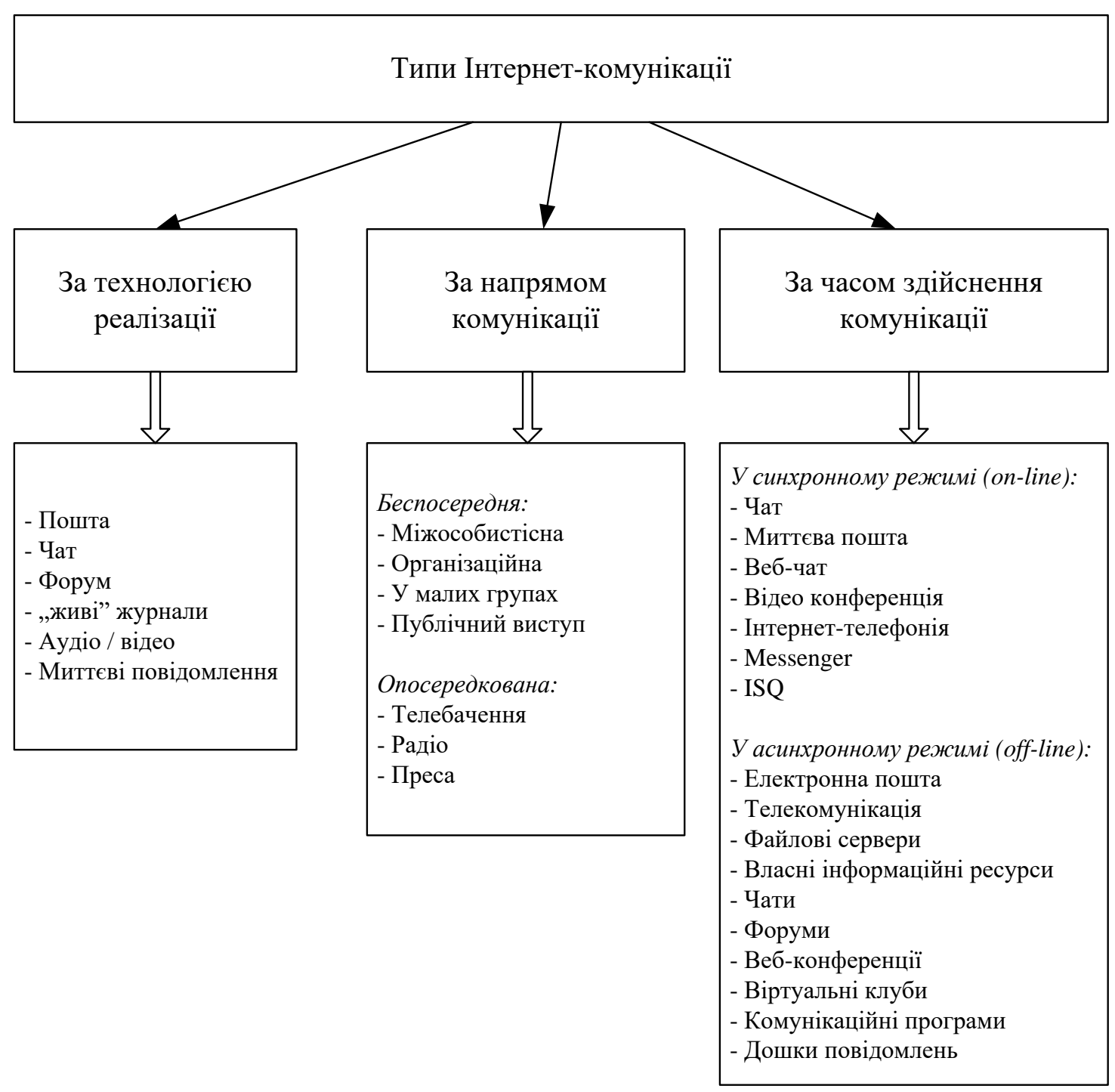

Рисунок 1 - Типи Інтернет-комунікації

Поряд 3 цим, майбутній фахівець 3 економки у процесі Інтернет-комунікації повинен володіти культурою мовлення, зокрема такими іiі показниками, як правильність, точність, виразність, чистота, доречність, логічність. Досягти високого рівня культури мовлення неможливо без наявності постійної потреби аналізувати, удосконалювати власне мовлення. Особливо важливим компонентом культури Інтернет-комунікації $є$ рефлексія, тобто розуміння власного внутрішнього світу, здатність зосередитись на собі. Рефлексія передбачає усвідомлення себе як носія культури, самооцінку особистісних якостей, поведінки, уміння їх коригувати.

Отже, культура Інтернет-комунікації є складовою професійної культури майбутнього економіста i передбачає оволодіння знаннями щодо Інтернетсередовища, технологіями й етичними нормами взаємообміну інформацією, уміннями й навичками організації Інтернет-взаємодії та використання їх у практичній діяльності.

Розробляючи методику формування у майбутніх економістів культури Інтернет-комунікації, ми грунтувались на наступному:
1) основними компонентами культури Інтернеткомунікації є культура пошуку інформації у мережі Інтернет, культура усного і писемного мовлення;

2) усвідомлення особистістю вагомості культури Інтернет-комунікації;

3) для формування культури Інтернет-комунікації у студентів економічного спрямування необхідно під час навчального процесу здійснювати раціональний добір навчального матеріалу; комплексне і творче застосування ефективних методів і прийомів, спрямованих на його засвоєння; вибір оптимального його поєднання з урахуванням особливостей студентів, групи.

Процес навчання має відбуватись як креативний процес комп'ютерно-опосередкованої комунікації, грунтуватись на принципі суб'єктивної взаємодії викладача і студентів, методи навчання повинні залучати студентів до активної Інтернет-комунікації. Методика формування у студентів економічного профілю Інтернет-комунікації передбачає використання технологій та методів, які згруповані у табл. 1. 
Таблиця 1 - Методика формування культури Інтернет-комунікації майбутніх економістів

\begin{tabular}{|c|c|c|}
\hline $\begin{array}{l}\text { № } \\
\text { 3/ח }\end{array}$ & Технології та методи & Сутність \\
\hline 1 & 2 & 3 \\
\hline 1. & $\begin{array}{l}\text { Комунікативно- } \\
\text { діяльнісний метод }\end{array}$ & $\begin{array}{l}\text { - відпрацювання мовленнєвої правильності; } \\
\text { - формування мовленнєвих умінь; } \\
\text { - багаторазове вживання у процесі комунікативної діяльності, що реалізу- } \\
\text { ється переважно в Інтернет-середовищі, матеріалу, що активізується }\end{array}$ \\
\hline 2. & $\begin{array}{l}\text { Технологія } \\
\text { інтерактивного } \\
\text { навчання }\end{array}$ & $\begin{array}{l}\text { взаємодія студентів як з однокурсниками, викладачами, іншими суб’єктами } \\
\text { комунікації в інформаційному середовищі Інтернет, так і спільна діяльність в } \\
\text { аудиторії }\end{array}$ \\
\hline 3. & $\begin{array}{l}\text { Технологія створення } \\
\text { portfolio «мовного } \\
\text { портфелю» }\end{array}$ & $\begin{array}{l}\text { оцінка діяльності студента за письмовими роботами, зібраними за результа- } \\
\text { тами використання різних технологій Інтернет }\end{array}$ \\
\hline 4. & $\begin{array}{l}\text { Метод «проектного } \\
\text { пошуку» }\end{array}$ & $\begin{array}{l}\text { планування і виконання проектів, щ поступово ускладняються: } \\
\text { - } \text { комунікативних (робота з комп’ютерними мережами, використання різних } \\
\text { засобів комп’ютерної комунікації); } \\
\text { - } \text { інформаційних (збір економічної інформації, ознайомлення учасників про- } \\
\text { екту з нею, їі аналіз, узагальнення фактів); } \\
\text { - інформаційно-комунікативних (гармонійне поєднання інформаційно- } \\
\text { пошукової та комунікативної діяльності студентів) }\end{array}$ \\
\hline 5. & Вправляння & $\begin{array}{l}\text { повторне виконання дій з метою їх засвоєння: пошук інформації; оцінка Інте- } \\
\text { рнет-ресурсу; оформлення результатів пошуку у вигляді посилання; форму- } \\
\text { вання списку ролевалентної інформації тощо }\end{array}$ \\
\hline 6. & $\begin{array}{l}\text { Лекційний метод в } \\
\text { електронному сере- } \\
\text { довищі }\end{array}$ & $\begin{array}{l}\text { розміщення текстових, аудіо-, відеоматеріалів курсу на веб-сайті, СД-дисках; } \\
\text { передача зображення і звуку під час відеоконференціязв’язку (телелекція, } \\
\text { медіа-лекція) }\end{array}$ \\
\hline 7. & $\begin{array}{l}\text { Робота в парах чи } \\
\text { групах }\end{array}$ & $\begin{array}{l}\text { грунтується на діалогічній формі навчання і сприяє розвитку комунікативних } \\
\text { умінь, культури поведінки }\end{array}$ \\
\hline 8. & $\begin{array}{l}\text { Методи «зараження» і } \\
\text { наслідування }\end{array}$ & $\begin{array}{l}\text { опосередковані методи в електронному середовищі, за яких дії і вчинки одних } \\
\text { учасників стають підставою для поведінки і дій інших }\end{array}$ \\
\hline
\end{tabular}

Отже, основою формування культури Інтернеткомунікації майбутніх економістів стала розроблена нами методика, згідно якої комплексно і творчо реалізовувались зазначені технології і методи, які дозволили органічно поєднати у процесі навчальної діяльності професійну і комунікативну підготовку студентів з урахуванням їх особливостей.

У процесі впровадження методики формування культури Інтернет-комунікації майбутніх економістів у навчальний процес постійно створювались ситуації успіху, оскільки переживання, що супроводжують досягнення успіху, впливають на подальший розвиток студента, визначають темпи і спрямованість його навчальної діяльності, спеціальну активність особистості.

Для порівняння реальної дійсності з запланованою використовувався педагогічний контроль.

Експериментальне дослідження передбачало конятатувальний, формувальний i контрольноузагальнюючий етапи. Констатувальний етап мав за мету виявити сформованість культури пошуку інформації у мережі Інтернет; писемного мовлення, piвень розвитку когнітивної сфери особистості. 3 цією метою використовувались такі методи діагностування сформованості культури Інтернет-комунікації у студентів як анкетування (запитання щодо розуміння соціальної, професійної й особистісної значущості комунікативних знань); тестування (визначення рівня знань щодо культури Інтернеткомунікації); самооцінка; опитування; інтерв'ю; виконання творчих завдань та проектів.
Формувальний етап експерименту передбачав апробацію методики формування у майбутніх економістів культури Інтернет-комунікації. У процесі контрольно-узагальнюючого етапу експерименту проводилась інтегральна обробка даних, співставлення результатів дослідження та їх аналіз. Узагальнені результати констатувального та прикінцевого діагностичного зрізу щодо рівня культури Інтернеткомунікації майбутніх економістів подано у табл. 2.

Таблиця 2 - Результати діагностики щодо рівнів культури Інтернет-комунікації (у \%)

\begin{tabular}{|l|c|c|c|c|}
\hline \multirow{2}{*}{ Рівні } & \multicolumn{2}{|c|}{$\begin{array}{c}\text { Початок } \\
\text { експерименту }\end{array}$} & \multicolumn{2}{|c|}{$\begin{array}{c}\text { Кінець } \\
\text { експерименту }\end{array}$} \\
\cline { 2 - 5 } & КГ & ЕГ & КГ & ЕГ \\
\hline Високий & 6 & 7 & 10,6 & 26,8 \\
\hline Середній & 45,5 & 43,7 & 51,5 & 53,5 \\
\hline Низький & 48,5 & 49,3 & 37,9 & 19,7 \\
\hline
\end{tabular}

Як бачимо з таблиці, у процесі навчання позитивні зміни відбулися як у контрольній, так і в експериментальній групах. Але в експериментальній групі вони були набагато значущі. Так в експериментальній групі високий рівень культури Інтернеткомунікації зріс на 19,8\%, а в контрольній - на 4,6\%. В експериментальній групі значно зменшились показники низького рівня (на 29,6\%), тоді як у контрольній групі лише на 10,6\%. 
ВИСНОВКИ. Таким чином, актуальність проблеми підготовки майбутніх економістів до Інтернет-комунікації набула об'єктивного перспективного характеру завдяки інформатизації суспільства, поширенню систем створення, збереження та використання інформації, розширенню комунікативних зв'язків економіста від контактів 3 найближчим оточенням до глобальних, міжкультурних комунікацій, що вимагає глибокого усвідомлення місця і ролі комунікації як засобу реалізації й координації економічної діяльності, активної реалізації можливостей комп'ютерних мереж для організації плідного спілкування у процесі професійної діяльності.

Теоретичне осмислення проблеми дало можливість підійти до розуміння інформаційно-пошукових комунікативних умінь як до комплексу комунікативних дій, заснованих на грунтовній теоретичній, практичній та технологічній підготовці, що дозволяє творчо використовувати комунікативні знання та навички для відбиття i перетворення Інтернеткомунікації.

Формуванню культури Інтернет-комунікації майбутніх економістів сприяють такі технології i методи, як: комунікативно-діяльнісний метод навчання, технологія інтерактивного навчання, технологія створення portfolio «мовного портфелю», метод проектного пошуку, вправляння.

На основі зіставлення результатів у проведеному педагогічному експерименті, їх кількісного і якісного аналізу виявлено, що реалізація методики формування у майбутніх економістів культури Інтернеткомунікації призвела до суттєвих статистично значущих змін, що підтверджує іiі ефективність.

До перспективних напрямів подальших наукових досліджень відносимо розробку шляхів розвитку й методику формування культури Інтернеткомунікації викладача вищого навчального закладу, конкретизацію завдань післядипломної економічної освіти, підвищення кваліфікації економістів.

\section{ЛІТЕРАТУРА}

1. Войнаровська О. Н. Перспективи застосування американського досвіду підготовки бакалаврів 3 економіки у вітчизняних вищих навчальних закладах. Педагогіка $і$ психологія професійної освіти. 2010. № 5. С. 7-11.

2. Гейзерська Р. А. Про необхідність формування професійно значущих якостей майбутніх магістрів економічного профілю. Вісн. Луган. наи. пед. унму імені Тараса Шевченка. Педагогічні науки. 2007. № 1. C. 241-243.

3. Ельбрехт О. М. Підготовка менеджерів у вищих навчальних закладах Великобританії, Канади, США (порівняльний аналіз): монографія; Ін-т вищ. Освіти АПН України. К.: Основа, 2009. 256 с.

4. Поясок Т. Б. Система застосування інформаційних технологій у професійній підготовці майбутніх економістів: монографія. Кременчук: ПП Щербатих O.B., 2009. 348 с.

5. Гриньова В. М. Аксіологічний підхід до проблеми педагогічної культури майбутнього вчителя. Шлях освіти. 2002. № 2. С. 2-6.

6. Куликова Л. В. Межкультурная коммуникация: теоретические и прикладные аспекты: монография. Красноярск: РИО КГПУ, 2004. 326 с.

7. Волкова Н. П. Професійно-педагогічна комунікація: теорія, технологія, практика: монографія. Д.: Вид-во ДНУ, 2005. 304c.

8. Розина И. Н. Педагогическая компьютерноопосредованная коммуникация: теория и практика: монография. М.: Логос, 2005. 439 с.

9. Barnes S. B. Computer-mediated communication: human to human communication across the Internet, Allynand Bacon, 2003. 156p.

10. West R. Introducing communication theory: analysis and application, 2nd ed., McGraw-Hill, 2004. $247 \mathrm{p}$.

\section{FORMING OF INTERNET COMMUNICATION CULTURE FOR FUTURE ECONOMISTS}

\section{T. Poyasok, O. Bespartochna}

Kremenchuk Mikhailo Ostrogradskyi National University

vul. Pershotravneva, 20, Kremenchuk, 39600, Ukraine. E-mail: poyasoktb@ukr.netbespartochnay@ukr.net

Purpose. The article aims to motivate the process of formation of Internet communication culture for future economists theoretically and develop a methodology for implementing this process. Methodology. The study uses a number of theoretical methods, including the following: theoretical and system analysis of psychological and pedagogical literature, comparison, systematization, abstraction and refinement, design, questioning, testing, interviewing, performing creative tasks and projects. Results. It has been established that formation of culture of Internet communication for future economists is assisted by technologies and methods: the communicative-active component of learning, the technology of interactive learning and portfolio making, projective search method and correction. Based on a comparison of the results of pedagogical experiment conducted, quantitative and qualitative analysis, it was found that the implementation of the method of Internet communication culture formation for future economists led to significant statistically significant changes, which confirms effectiveness. Originality. For the first time, the "culture of Internet communication" phenomenon was uncovered and methodology was presented for forming Internet communication culture for future economists, its components were characterized, and the choice of technologies was motivated to facilitate implementation. Practical value. The study conducted by the authors on the formation of culture of Internet communication for future economists has made it possible to determine the most effective methods and technologies in the process of professional training. The results of study can be used in development of modern programs and special courses for future economists training, in accordance with which they are trained. Findings. Studying the problem of forming the Internet culture of future economists in the process of vocational training allowed us to approach the understanding of information and search-based communicative skills as a set of communicative actions based on substantial theoretical, practical and technological training that allows creative use of communicative knowledge and skills to reflect and transform 
Internet communication. The development of culture of Internet communication for future economists is promoted by such technologies and methods as communicative-activity learning method, interactive learning technology, portfolio technology.

Key words: Internet communication, culture, economics, technology, methods, language label, least short label.

\section{REFERENCES}

1. Voinarovska, O. N. (2010), "Prospects of applying the US experience in training bachelors of economics in domestic higher education institutions", Pedagogy and psychology of vocational education, 2010, No 5, pp. 7-11.

2. Heizerska, R. A. (2007), “On the necessity of formation of professionally significant qualities of future masters of economic profil", Bulletin of the Taras Shevchenko Lugansk National Pedagogical University, No 1. pp. 241-243.

3. Elbrekht, O. M. (2009), Pidhotovka menedzheriv $u$ vyshchykh navchalnykh zakladakh Velykobrytanii, Kanady, SSHA(porivnialny I analiz) [Training of Managers in Higher Education Institutions in Great Britain, Canada, USA (Comparative Analysis)], Osnova, Kyiv, Ukraine.

4. Poiasok, T. B. (2009), Sysytema zastosuvannia informatsiinykh tekhnolohiy u profesiinii pidhotovtsi maibutnikh ekonomistiv [System of application of information technologies in the training of future economists], PP Shcherbtykh O. V., Kremenchuk, Ukraine.
5. Hrynova, V. M. (2002), “Aksiolohichnyi pidkhid do problemy pedahohichnoi kultury maibutnoho vchytelia"[Axiological approach to the problem of the pedagogical culture of the future teacher], Shliakhosvity [The path of education], 2002, No2, pp. 2-6.

6. Kulikova, L. V. (2004), Mezhkulturnaya kommunikatsiya: teoreticheskieiprikladnyie aspektyi [Intercultural Communication: Theoretical and Applied Aspects], RIOKGPU, Krasnoyarsk, Pussia.

7. Volkova, N. P. (2005), Profesiino-pedahohichna komunikatsiia: teoriia, tekhnolohiia, praktyka [Professional-pedagogical communication: theory, technology, practice],Vyd-vo DNU, Donetsk, Ukraine.

8. Rozina, I. N. (2005), Pedagogicheskaya kompyuterno-oposredovannaya kommunikatsiya: teorya i praktika [Pedagogical computer-mediated communication: theory and practice], Logos, Moskva, Pussia.

9. Barnes, S. B. (2003), Computer-mediated communication: human to human communication across the Internet, Allynand Bacon, USA.

10. West, R. (2004), Introducing communicati on theory: analysis and application, McGraw-Hill, Great Britain.

Стаття надійшла 20.03.2019. 